\title{
Covid-19 Experiences of a new training programme for final-year medical students during the COVID-19 pandemic
}

\author{
Authors: Jane Simpson, ${ }^{A}$ Irene Gafson, ${ }^{B}$ Mumtaz Mooncey, ${ }^{C}$ Johnny Swart ${ }^{D}$ and Caroline Fertleman ${ }^{\mathrm{E}}$
}

\begin{abstract}
The COVID-19 pandemic has seen the rapid introduction of innovative schemes to maximise the medical workforce and utilise untapped capacity within the NHS. One such innovation was the recruitment of final year medical students as medical support workers (MSWs) immediately following their final examinations and 4 months before they would have traditionally been employed in their foundation year 1 (FY1) roles. In this article we will describe how a unique programme, with a focus on welfare and pastoral support, was developed and implemented at a hospital in North London and illustrate why the overwhelmingly positive feedback from both the participants and their supervisors has had implications for how medical student training has been shaped for the September 2020 intake at this hospital.
\end{abstract}

KEYWORDS: Training, COVID-19, pastoral support, multidisciplinary learning, apprenticeship

DOI: 10.7861/fhj.2020-0197

\section{Background}

In March 2020, final year medical students at University College London ( $\mathrm{UCL}$ ) completed their final examinations in the knowledge that their remaining clinical training, which constituted their electives and 'preparation for practice' modules, had been cancelled due to the coronavirus pandemic. A day after receiving their results they received invitations to volunteer to help relieve some of the anticipated strain on the existing medical workforce during the crisis. The offer, made by Whittington Health in North London, was a three-month paid contract as a medical support worker (MSW), with subsidised accommodation if required, and 47 students out of a cohort of 303 took up the offer. It is worth noting that many other students from this year group, and indeed

Authors: Alocum paediatric consultant, Whittington Health NHS Trust, London, UK; B Blocum obstetric and gynaecology consultant, Whittington Health NHS Trust, London, UK, and lecturer in medical education, University College London Medical School; ' paediatric trainee, Whittington Health NHS Trust, London, UK; ${ }^{D}$ consultant physician and geriatrician, Whittington Health NHS Trust, London, UK; Eundergraduate lead, Whittington Campus UCL Medical School from other years of training, took up similar offers to contribute in partner hospitals.

This was an extraordinary time and we were asking for an extraordinary commitment from our final year medical students. Key to the success and ethics of the MSW programme would be the pastoral care and support provided, and so the Whittington team consciously placed these at the heart of programme development and implementation.

The clinical placement commenced on 6 April 2020 with a 2-day induction programme. Due to the unique nature of the programme we focused heavily on wellbeing, resilience and safety, with detailed guidance on personal protective equipment (PPE), as well as the usual induction components such as IT training, infection control, cannulation and basic life support. A troubleshooting session with an existing FY1 was provided along with substantial time for teambuilding and discussion of welfare and support. Each MSW was allocated a mentor from the existing FY1 cohort as well as a consultant educational supervisor. The induction ended with MSWs being taken by their teams to their areas of work by their allocated supervisors.

We held face-to-face feedback sessions every $2-4$ weeks to help identify and resolve any practical and pastoral issues. As well as a full group session, there were small breakout groups to ensure everyone felt comfortable to speak out. We offered a weekly teaching session covering FY1 topics and a half day of emergency simulation training. At the end of the programme, we asked the MSWs to complete an online qualitative questionnaire.

\section{Methods for qualitative analysis of the programme}

This was an evaluation of a teaching programme in the context of a unique educational landscape and therefore formal ethics approval was not sought. The data were collected anonymously and the responses stored securely. The questions were devised by the team involved in the project as it was important to receive specific feedback on this unique programme and use the findings to guide future undergraduate placements.

We chose a qualitative questionnaire with multiple free-text responses which was conducted anonymously online at the end of the programme. This allowed an in-depth understanding of their perspective of the programme.

All of the MSWs completed this.

\section{Questionnaire design}

The 18 questions explored the MSWs' motivations, expectations and experiences, and the impact of the programme (see Box 1). 


\section{Box 1. Questions asked in the end of placement questionnaire}

$>$ What was your motivation for becoming a medical support worker (MSW)?

$>$ What made you choose to apply for a role at the Whittington?

> What were you expecting to do as part of your role?

$>$ Did you feel that the induction prepared you for your role?

$>$ What best describes the team you have been a part of?

$>$ Do you know who your direct clinical supervisor is? ( $\mathrm{Y} / \mathrm{N})$ If $\mathrm{Y}$, were they supportive to your needs?

$>$ What were your roles within your team?

$>$ Do you feel that you received enough pastoral/emotional support during the placement?

> What have been the best parts of being an MSW?

> What have been the biggest challenges of being an MSW?

> Would you recommend a younger year student to apply for an MSW role if it runs again?

> Has the MSW programme made you think differently about how medical students carry out their clinical placements? Please detail.

$>$ Do you think your experience as an MSW has prepared you for being an $\mathrm{FY}$ doctor?

> How do you think your experience will influence you in your career as a doctor?

> What were your overall thoughts about the MSW programme?

> What did you think of the formal teaching programme?

$>$ What did you think of the feedback sessions?

> What did you think of the pastoral care and who provided it?

\section{Thematic analysis}

We took a constructivist approach to analysing the free-text responses, using a structure advocated by Braun and Clarke. Two of the authors were independently immersed in the dataset and an initial set of codes was created to describe the entire dataset. These codes were then grouped into overarching themes. The codes and themes were then discussed and compared until there was an agreed consensus and then a third author ensured that all the dataset could be placed into the agreed themes and that data saturation was achieved.

\section{Results}

Three overarching themes were identified: giving, taking and belonging. Within each of these there were several subthemes. These are illustrated in Fig 1. In this section, we will present each theme with some illustrative quotations.

\section{Theme 1: Giving}

'Giving' can be broadly divided into two main areas: physical giving, such as time and the physical assistance which was provided; and emotional giving, including compassion, kindness, emotional and moral support (see Table 1).

The early months of the COVID-19 pandemic were marked by notable demonstrations of selflessness, kindness and generosity
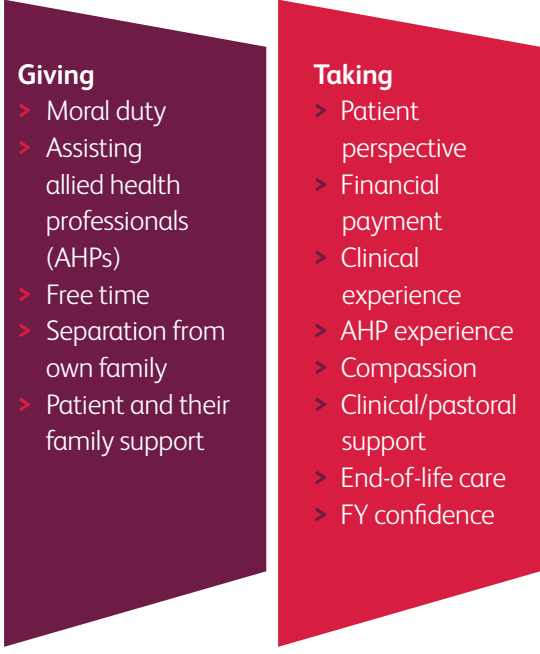

\section{Belonging}

$>$ Sense of value

$>$ Sense of

purpose

$>$ Team

Fig 1. Representation of themes and subthemes.

within our society. ${ }^{2}$ The MSW programme reflected this and questions which assessed underlying motivations for volunteering uncovered a range of similar themes. Having just finished medical school, the MSWs possessed a wealth of skills which could be used to benefit others. Many comments reflected a deep sense of altruism, with MSWs frequently describing feeling compelled and morally obliged to contribute their time and skills to help others at such a challenging time. In many cases, this sense of obligation led to personal sacrifices such as separation from family and accepting personal health risks.

\section{Theme 2: Taking}

The second theme of 'taking' captures what the MSWs gained from their experience. It highlights the synchrony of both giving and taking during this time. While the MSWs were willing to

\section{Table 1. Illustrative quotations for 'Giving' theme}

\section{Subtheme} Quotation

Moral duty

'I felt like I had to do something to help in the middle of a crisis. I felt like I couldn't sit at home with skills that could be used to help'

'I wanted to help and be useful during the COVID pandemic'

Assisting 'Varied role - started off helping wherever allied health

professionals Did some 1:1 nursing with patients at the needed: jobs rounds, bloods, feeding etc. end of their life'

Free time 'I didn't want to sit at home twiddling my thumbs'

Separation from 'Being separated from family when we family suffered a bereavement of our own'

Patient and family support
'Knowing that these patients were separated from family and being the person sat by the bedside holding their hand in their last moments' 
Table 2. Illustrative quotations for 'Taking' theme

\begin{tabular}{|c|c|}
\hline Subtheme & Quotation \\
\hline Patient perspective & $\begin{array}{l}\text { 'Being able to be a proper doctor, see } \\
\text { patients and have great clinical experience } \\
\text { in A\&E' }\end{array}$ \\
\hline Financial payment & $\begin{array}{l}\text { 'Wanted to keep busy and earn money } \\
\text { during lockdown' }\end{array}$ \\
\hline Clinical experience & $\begin{array}{l}\text { 'I've had opportunities unavailable to } \\
\text { most of my peers. I have had the ability } \\
\text { to progress in a supportive and friendly } \\
\text { environment' }\end{array}$ \\
\hline $\begin{array}{l}\text { Allied health } \\
\text { professional } \\
\text { experience }\end{array}$ & $\begin{array}{l}\text { 'Learning about the different roles of the } \\
\text { healthcare team' }\end{array}$ \\
\hline Compassion & 'I truly feel I have grown as a person' \\
\hline $\begin{array}{l}\text { Clinical/pastoral } \\
\text { support }\end{array}$ & $\begin{array}{l}\text { 'My highlight was probably meeting my } \\
\text { team and bonding with them so much - I } \\
\text { didn't expect to come away from this having } \\
\text { made such firm friends' }\end{array}$ \\
\hline End of life care & $\begin{array}{l}\text { 'I've gained a unique perspective on the } \\
\text { importance of the multidisciplinary team } \\
\text { (MDT) and on death and how to care for } \\
\text { patients at the end of their lives' }\end{array}$ \\
\hline FY1 confidence & $\begin{array}{l}\text { 'Getting comfortable with life as a doctor } \\
\text { which will help enormously for starting in } \\
\text { August' }\end{array}$ \\
\hline COVID anxiety & $\begin{array}{l}\text { 'Nice to start work with friends from uni } \\
\text { during such a strange time' }\end{array}$ \\
\hline
\end{tabular}

make their own sacrifices to create a positive change, they also benefitted during the process (see Table 2 ).

From a clinical perspective, all of the participants found this to be an extremely beneficial experience and that they gained a great deal in terms of preparation for their future work as doctors in training. In particular, many of them were exposed to very challenging clinical situations, such as end-of-life care, within the context of restricted visiting and medically managing an emerging and poorly understood disease. This provided them with the opportunity to develop their clinical skills, clinical judgement and confidence.

\section{Theme 3: Belonging}

'Belonging' was the most recurrent, overarching theme highlighted in the feedback. This was particularly true when MSWs were asked to describe the best parts of the programme or give their overall thoughts (see Table 3). A large number of participants emphasised how good it had felt to be a valued team member, with a true sense of purpose. In fact, this was of such significance that many stated that they had never felt more welcomed into any team before. Comparisons were made to other placements at medical school, and overall the support and care demonstrated by peers and other members of the multidisciplinary team (MDT) was felt to be far superior to that which they had previously experienced.

Not only did the MSWs describe feeling appreciated by others in the team, but they also commented on feeling that their contribution to the clinical and holistic care of patients had been truly invaluable.

Table 3. Illustrative quotations for 'Belonging' theme

\section{Subtheme}

Sense of value

Team

\section{Quotation}

'It's been a real privilege to be part of the COVID response and to feel valued by the team. Everyone has been so caring, friendly and supportive. It's been the perfect start to my medical career and I will always treasure my memories of being an a medical support worker at the Whit'

\section{Sense of purpose 'I felt like I had contributed to a crisis in the best way that I could and I can leave feeling proud of myself'}

'They were all so welcoming and made us really feel part of the team. They never made us feel inferior but were equally so good at knowing when we would need an extra hand/ support. Thanks so much!!'

"My highlight was probably meeting my team and bonding with them so much I didn't expect to come away from this having made such firm friends'

\section{Conclusions and recommendations for undergraduate trainers}

The delivery of undergraduate training in the 2020-2021 academic year is going to be a challenge. ${ }^{3}$ We believe that the findings from our MSW questionnaires could serve to inform those trying to provide high quality and positive undergraduate experiences in the post-COVID-19 landscape.

Students need to feel that they belong: to their peers, to the profession and to the wider health community. This can be better achieved through an apprenticeship-style model of clinical placements, with programme directors aiming to harness student enthusiasm and to help students feel relevant to and part of the organisation as a whole. Among those who volunteered to be MSWs, there was an overwhelming sense of goodwill and enthusiasm. They felt a sense of purpose and belonging within the organisation, and this continued throughout their placements. Key to this was the knowledge that they were wanted and appreciated for what they could give as well as take from the existing workforce.

Medical students should be encouraged to work closely with nurses and AHPs. They fundamentally want to feel involved and anyone in the healthcare team can help to achieve this. The value MSWs placed on working alongside the wider MDT was immeasurable. This close working allowed them to acquire new practical skills but also to gain a true understanding of the role and contribution of these staff members. This in turn contributed to more effective and collaborative team working.

Medical students should have regular, scheduled feedback sessions during their placements. These should be held with the same faculty and away from the clinical workplace. This will provide a safe space for students to share any of the emotional burden associated with the delivery of care, especially in the context of the pandemic. The existence of an open forum to provide pastoral support and address any communal or individual concerns was intrinsic to the success of our MSW programme. 
Other educational programmes during the pandemic have described this as 'psychological PPE'. ${ }^{4}$ Feeding back on any actions to their concerns contributed to the MSWs' sense of belonging and enabled them to realise that their concerns were important and listened to.

Programme directors should make it clear to students that they will need a flexible approach to their training. The MSW programme only lasted 3 months but even during this short time ever-changing clinical need and circumstances required us to adapt roles and placements. Being transparent about this uncertainty ensured that the MSWs stayed on board with this and were able to cope with the changes made to their clinical roles and responsibilities.

Changes have been made to the 2020-2021 clinical undergraduate placements across the UCL partner hospitals, in part informed by our MSW experience. Overall, we have moved to an apprenticeship-style model with students placed on one site for a whole year. At our Trust, the students receive a full-site induction and key pastoral support contacts have been identified at all levels of seniority. An emphasis has been placed on the need for students to be proactive and flexible in their approach to clinical learning. To nurture the positive MDT approach and culture, the nursing, midwifery and AHPs have been made aware of these changes and encouraged to support them and involve the students at a practical level.

\section{References}

1 Braun V, Clarke V. Using thematic analysis in psychology. Qual Res Psychol 2006;3:77-101.

2 BBC News. Coronavirus kindness: The people offering help as the virus spreads. www.bbc.co.uk/news/uk-51908023 [Accessed 20th September 2020].

3 Gill D, Whitehead C, Wondimagegn D. Challenges to medical education at the time of physical distances. Lancet 2020;396:77-9.

4 Hardacre J, Margetts A. Psychological PPE: survival kit for creating a safer culture in the Covid-19 context. https://blogs.bmj.com/ bmjleader/2020/04/15/psychological-ppe-survival-kit-for-creatinga-safer-culture-in-the-covid-19-context/.

Address for correspondence: Dr Irene Gafson, Whittington Health, Magdala Avenue, London N19 5NF.

Email: irenegafson@doctors.org.uk 